\title{
Perancangan Fotografi Ragam Hias Damar Kurung Khas Gresik dalam Fashion
}

\author{
Melia Christie $^{1^{*}}$, Petrus Gogor Bangsa ${ }^{2}$, Aniendya Christianna ${ }^{3}$ \\ 1,3 Program Studi Desain Komunikasi Visual, Fakultas Seni dan Desain, \\ Universitas Kristen Petra, Jl. Siwalankerto No. 121-131 Surabaya \\ 2 Program Studi Desain Komunikasi Visual, Fakultas Seni Rupa, \\ Institut Seni Indonesia, Jl. Parangtritis KM 6, Yogyakarta \\ *Penulis korespondensi; Email: meliachr@gmail.com
}

\begin{abstract}
Abstrak
Generasi muda masih mengenal ragam hias Damar Kurung sebagai bentuk lampionnya. Padahal, Damar Kurung merupakan sebutan untuk ragam hias yang menghiasi setiap sisi lampion dan sudah diresmikan sebagai warisan budaya tak bendawi nasional. Analisis data pada perancangan ini menggunakan metode deskriptif kualitatif untuk mengetahui fenomena yang berkembang di kalangan subjek penelitian dengan lebih dalam, serta pemahaman mengenai ragam hias Damar Kurung. Tujuan perancangan ini untuk memperkenalkan Damar Kurung sebagai ragam hias pada generasi muda melalui fotografi fashion. Ragam hias Damar Kurung diaplikasikan dalam busana bergaya kasual. Pendekatan fotografi bertujuan agar dapat menunjukkan visual ragam hias Damar Kurung dengan baik. Perancangan ini menghasilkan fashion item, merchandise, dan promotion tools berupa postcard, buku katalog, dan kalender.
\end{abstract}

Kata Kunci: Fotografi, Fashion, Ragam Hias Damar Kurung, Damar Kurung Gresik.

\begin{abstract}
The younger generation still identifies Damar Kurung as the name of the lanterns' form. Whereas Damar Kurung is the name of the pattern which decorates each side of the lantern and has been inaugurated as a national intangible cultural heritage. This research uses descriptive qualitative methods to find out the phenomenon that is growing among subjects deeply and to understand the knowledge about the Damar Kurung pattern. The purpose of this project is to introduce Damar Kurung as a pattern to the young generation through fashion photography. Damar Kurung pattern is applied to casual fashion. The photography approach aims to show visuals of the Damar Kurung pattern aesthetically. This project produces fashion items, merchandise, and promotion tools such as postcards, a catalog book, and a calendar.
\end{abstract}

Keywords: Photography, fashion, Damar Kurung pattern, Damar Kurung Gresik.

\section{Pendahuluan}

Kabupaten Gresik adalah salah satu dari banyak kabupaten yang ada di Indonesia terletak di Provinsi Jawa Timur. Menurut Thomas Stamford Raffles dalam buku yang berjudul "The History of Java", nama Gresik berasal dari kata giri gisik yang memiliki makna "gunung di tepi pantai". Hal itu berdasarkan pada topografi Gresik yang berada di pinggir pantai (Gitgita, 2018). Selain itu, Gresik juga disebut sebagai kota santri karena mayoritas masyarakat disini pemeluk agama Islam. Terdapat pula makam dari dua anggota Walisanga, yaitu Syekh Maulana Malik Ibrahim dan Sunan Giri. Begitu pula makam Siti Fatimah binti Maimun yang dikenal sebagai penyebar agama Islam di pulau Jawa serta banyaknya pondok pesantren dan sekolah Islam yang dibangun di Gresik (Gitgita, 2018).

Selain peninggalan Islam, Gresik juga memiliki kebudayaan ragam hias Damar Kurung. Ragam hias Damar Kurung dipopulerkan oleh mendiang Masmundari, namun sudah ada dan menjadi salah satu kesenian Islam sejak masa pemerintahan Sunan Prapen (Annisaa, 2014: 6). Damar Kurung adalah kap lampu yang berbentuk kubus dengan lukisan di setiap sisinya. Lukisan itulah yang disebut sebagai Damar Kurung. Bentuk karakternya sendiri digambar dengan model yang pipih menghadap ke 
samping untuk karakter manusia, sama seperti wayang kulit atau gambar litograph dari Mesir (Koeshandari, 2009:90). Namun pada saat ini, kemunculan budaya baru akhirnya secara tidak langsung mengikis kebudayaan asli daerah dan berpotensi membuat kebudayaan asli daerah tersebut punah, termasuk ragam hias Damar Kurung yang tidak lagi menjadi antusiasme generasi muda Indonesia. Banyak dari generasi muda masih beranggapan bahwa Damar Kurung adalah sebutan dari bentuk lampionnya. Padahal sebenarnya Damar Kurung (yang diresmikan sebagai warisan budaya tak bendawi nasional pada 4 Oktober 2017 oleh Kementerian Pendidikan dan Kebudayaan Republik Indonesia), yang artinya Damar Kurung adalah sebutan untuk ragam hiasnya, bukan wujud lampionnya (Editor02, 2017).

Hal tersebut dapat dilihat pada perkembangan busana dan motif batik yang ada di Kota Gresik. Dari beberapa motif batik yang menjadi ciri khasnya, ada batik di Gresik yang mengangkat ragam hias Damar Kurung sebagai motifnya, namun motif batik Damar Kurung yang diangkat masih dalam bentuk lampionnya. Hal itu menjadi salah satu alasan mengapa banyak dari generasi muda kurang mengenal Damar Kurung sebagai ragam hias.

Ada pula perancangan sebelumnya, ragam hias Damar Kurung sudah pernah dijadikan sebagai salah satu motif dalam batik khas Gresik yang dirancang oleh Aniendya Christianna dan Luri Renaningtyas, sehingga motif batik Damar Kurung bukan lagi bergambar lampion namun karakter dalam ragam hias Damar Kurung itu sendiri yang memperlihatkan identitas perempuan Jawa dan perannya dalam masyarakat (Christianna \& Renaningtyas, 2017/2018). Namun batik motif ragam hias Damar Kurung hasil perancangan Aniendya Christianna dan Luri Renaningtyas tersebut hanya berupa lembaran kain. Adapun busana dalam motif-motif batik Gresik dibuat dengan gaya yang formal dan kebanyakan pengguna busana tersebut adalah orang tua. Maka dari itu ragam hias Damar Kurung perlu diaplikasikan pada busana yang lebih kasual dan gaya yang lebih disesuaikan dengan trend di kalangan generasi muda untuk mendekatkan kembali ragam hias Damar Kurung dengan generasi muda melalui fotografi.
Artikel ini untuk mendeskripsikan bagaimana merancang karya fotografi yang diperlukan untuk menampilkan visual fashion ragam hias Damar Kurung pada generasi muda. Hasil dari fotografi tersebut juga digunakan untuk memberikan referensi pada generasi muda dalam padu-padan fashion ragam hias Damar Kurung dan juga untuk mempermudah dalam mendeskripsikan dan memberikan visual tema ragam hias Damar Kurung dalam fashion tersebut.

\section{Fotografi}

Fotografi merupakan suatu cara berkomunikasi menggunakan gambar sebagai medianya. Berbeda dengan kata-kata yang diungkapkan secara tertulis maupun verbal yang tidak ada visualnya, fotografi merupakan bentuk komunikasi yang dapat dipahami oleh dunia karena terdapat gambar yang mudah untuk ditafsirkan maknanya. Menurut Michael Langford, fotografi adalah kombinasi antara imajinasi dengan desain visual, keterampilan, dan kemampuan mengorganisasikan secara praktis. Sehingga dapat disimpulkan bahwa fotografi bukan hanya menangkap gambar, namun juga menata objek yang akan dipotret agar dapat mencapai nilai estetika yang baru tanpa kehilangan maknanya (Awaliyah, 2020).

Fotografi dalam perancangan ini merupakan fotografi fashion. Fotografi jenis ini lebih fokus pada memotret untuk menampilkan mode busana dan barang pendukung fashion lainnya yang berkaitan dengan gaya hidup yang sedang menjadi trend pada masa itu, untuk diterbitkan pada majalah fashion, industri periklanan atau beredar di kalangan desainer (Kusumabrata, 2015). Fotografi fashion mengutamakan tampilan mode dan gaya hidup yang diperkuat dengan aksesoris, dandanan yang sesuai dan efek cahaya. Untuk peraga atau model fashion, pose yang diperagakan berfungsi untuk menonjolkan busana dan perlengkapan yang sedang dikenakan.

Menurut Andina (2020), terdapat beberapa jenis fotografi fashion:

1. Editorial Fashion Photography: Gaya busana yang dikenakan pada kategori ini terkesan glamor dan ditampilkan dalam majalah fashion, buku, poster, dan lain sebagainya. Fotografi jenis ini memiliki konsep, gagasan dan cerita yang ingin 
disampaikan melalui model yang memerankan cerita tersebut lewat ekspresi dan pose yang sudah ditentukan.

2. High Fashion Photography: Menampilkan busana dari brand kelas atas seperti Gucci, Prada, Hermes, dan lain sebagainya dalam bentuk iklan. Konsep yang digunakan sederhana tapi masih terlihat elegan dengan menampilkan supermodel dan selebriti kelas atas.

3. Catalogue Fashion Photography: Lebih mengedepankan konsep yang sederhana, tujuannya agar pengamat fokus pada penampilan produk busana maupun aksesoris yang ditawarkan.

4. Street Fashion Photography: Lebih menonjolkan pada gaya busana yang sedang menjadi trend di seluruh penjuru dunia atau yang dikenakan orang-orang pada umumnya. Properti yang digunakan untuk pemotretan ini juga menggunakan barang-barang yang sering ditemui di luar.

\section{Fashion}

Menurut Malcolm Barnard, pengertian fashion dari sisi etimologi berhubungan dengan kata "factio" yang berasal dari bahasa Latin yang artinya "membuat". Maka dari itu, fashion merupakan suatu aktivitas yang sedang dilakukan oleh seseorang. Namun pada saat ini, makna tersebut semakin menyempit sehingga kini fashion lebih mengarah pada suatu mode yang dipakai individu maupun kelompok seperti gaya busana maupun perhiasannya. Sedangkan menurut Thomas Karlyle, fashion diartikan sebagai kulit segi social yang mengandung pesan atau gaya hidup individu maupun kelompok tertentu yang menjadi bagian dari kultur sosial (dalam Setiawan, 2020). Dengan kata lain, fashion dapat menunjukkan identitas diri pemakainya. Dapat disimpulkan bahwa fashion merupakan gaya hidup seseorang yang digunakan dalam keseharian meliputi gaya busana, gaya rambut, gaya aksesoris, gaya dandanan dan lain sebagainya yang mampu menunjang penampilan seseorang.

Menurut Thalia (2019), terdapat macammacam gaya fashion yaitu :

1. Casual style: mengutamakan gaya yang sederhana dan nyaman untuk digunakan. Gaya kasual identik dengan gaya pakaian non-formal sehingga cocok digunakan kegiatan sehari-hari.
2. Glamor style: identik dengan kesan yang mewah, penuh gemerlap dan digunakan untuk menunjukkan status sosial seseorang.

3. Classic style: lebih mengutamakan kenyamanan dalam padu-padan berpakaian dengan gaya yang sederhana tapi juga dapat menunjukkan sisi yang elegan.

4. Bohemian style: Memiliki gaya desain yang artistik dengan pola yang rumit. Kebanyakan bentuk baju gaya bohemian adalah blus khas gadis desa, ponco hippie, dipenuhi motif, corak, pola dan tekstur yang rumit dan eksotis.

5. Arty style: Gayanya hampir sama seperti gaya bohemian, namun pola dan coraknya unik dan berbeda dengan gaya lain. Kombinasi warna gaya arty menggunakan warna yang cerah.

6. Chic style: Memiliki gaya yang sederhana namun juga dapat digunakan untuk acara yang formal. Kesan yang dibawakan adalah klasik tapi tetap terlihat stylish.

\section{Peran Fashion dalam Upaya Melestarikan Budaya Daerah}

Pada era globalisasi, fashion dibuat tidak hanya untuk dipakai maupun menunjukkan identitas diri saja, tapi juga punya nilai tambah sebagai alat untuk melestarikan budaya Nusantara. Hal ini terbukti dengan adanya desainer seperti Barli Asmara, Edward Hutabarat dan masih banyak lagi desainer yang menyelipkan unsur seni lokal ke dalam busananya seperti batik atau corak adat lainnya. Berkembangnya batik di kalangan desainer Indonesia juga didasari oleh diresmikannya batik sebagai warisan budaya Indonesia UNESCO pada hari Jumat tanggal 02 Oktober 2009, dan hari itulah ditetapkannya sebagai Hari Batik Nasional (Nahak, 2019). Berdasarkan pendapat Koentjaraningra dalam Nahak (2019) bahwa kebudayaan akan terus mengalami perubahan dari waktu ke waktu sehingga masyarakat yang memiliki kebudayaan tersebut harus tetap mengenal, memelihara dan melestarikan kebudayaan yang dimiliki agar setiap perubahan yang terjadi tidak menghilangkan karakter asli dari kebudayaan itu sendiri. Dapat disimpulkan bahwa walaupun Damar Kurung yang mulanya berbentuk lampion kemudian diaplikasikan dalam fashion, hal tersebut tetap tidak menghilangkan karakter asli ragam hias Damar Kurung itu sendiri. 


\section{Damar Kurung}

Ragam hias Damar Kurung mirip dengan gambar anak-anak, tetapi bukan lukisan anakanak (Koeshandari, 2009: 93). Hal tersebut karena gaya lukis Masmundari yang lugu, polos, spontan, lucu dan indah. Bentuk figur yang digambarkan adalah sosok-sosok manusia yang sedang melakukan aktivitas sehari-hari dengan model pipih menghadap ke samping berjejeran atau ditumpuk dari atas ke bawah dan dari bawah ke atas, menggunakan sekat berupa garis pembatas, penggunaan warnawarna yang cerah, tunggal dan rata, bergaya stilistik seperti wayang kulit atau gambargambar lithograph dari Mesir. Penggambaran kostum dan latar kejadian lebih mendekati realitas masa kini.

Penggambaran karakter dalam cerita Damar Kurung memiliki ciri khasnya masing-masing, yang dapat dilihat dari atribut yang digunakan karakter atau benda-benda disekitar karakter tersebut. Contohnya seperti cerita tentang Ramadhan berjudul "Shalat Tarawih", "Idul Fitri", yang selalu ditandai dengan karakter orang yang mengenakan mukenah, sarung, dan berkelompok yang menandai sedang melakukan shalat berjamaah di masjid.

\section{Metode}

Pengumpulan data dibagi menjadi 2 bagian yaitu data primer dan data sekunder.

1. Data Primer:

a. Wawancara dengan Novan Effendy pendiri Damar Kurung Institute mengenai detail ragam hias Damar Kurung dan juga dengan komunitas Damar Kurung, bertujuan untuk mengetahui lebih dalam mengenai sejarah Damar Kurung, maupun ketentuan-ketentuan yang tidak bisa dilanggar terkait ragam hias Damar Kurung.

b. Tinjauan pustaka yang diperlukan untuk perancangan ini adalah jurnal mengenai fenomena yang terjadi pada kehidupan sosial seputar kebiasaan dan reaksi target audience mengenai pengetahuan kebudayaan lokal serta sejarah dan pengetahuan mengenai ragam hias Damar Kurung. Fenomena ini berfungsi untuk mendukung teori yang didapat dari datadata primer. Data ini didapatkan dari artikel dan jurnal yang ada di internet maupun berupa fisik.

2. Data Sekunder: Melakukan observasi untuk keperluan data sekunder, dengan cara pengamatan secara langsung pada target audience yang bersangkutan dan juga didapat dari berita mengenai fenomena di kalangan target audience, bertujuan untuk mengetahui fashion trend di kalangan target audience lebih dalam, serta seberapa dalam target audience mengenal ragam hias Damar Kurung.

Analisis data menggunakan metode deskriptif kualitatif, yaitu mengumpulkan data dari hasil wawancara dan literatur. Pola yang digunakan untuk menganalisa kumpulan data tersebut adalah 5W+1H. Berdasarkan hasil analisis data, dapat disimpulkan bahwa target audience perempuan di Surabaya dan Gresik dengan dominan usia 20-25 tahun kurang mengenal Damar Kurung sebagai ragam hias dan bahkan ada yang belum mengenal Damar Kurung, sehingga perlu adanya media yang menarik perhatian target audience untuk memperkenalkan ragam hias Damar Kurung yaitu perancangan fotografi dengan konsep editorial fashion photography dengan menggunakan gaya fashion kasual yang nyaman untuk digunakan sehari-hari yang disesuaikan dengan selera target audience. Hasil foto dari perancangan beserta penjelasan konsep perancangan ini nantinya akan di upload ke sosial media berbasis visual yang sering digunakan oleh target audience yaitu Instagram. Damar Kurung sendiri dapat diaplikasikan pada fashion dengan memperhatikan pakem-pakem yang sudah ditentukan yaitu kepala yang menghadap ke samping dan adanya ornamen-ornamen dalam Damar Kurung. Tema Damar Kurung yang akan digunakan sebagai pattern dalam perancangan ini adalah tema profan yang menggambarkan kehidupan target audience masa kini.

\section{Pembahasan}

\section{Konsep Perancangan}

Konsep perancangan fotografi ini dibuat berdasarkan data mengenai sejarah dan perkembangan ragam hias Damar Kurung yang didapat melalui berbagai sumber. Kemudian dari data tersebut, ragam hias Damar Kurung diaplikasikan pada produk fashion yang nantinya akan dikenakan model pada saat pemotretan. Perancangan ini bertujuan untuk menampilkan dan mendekatkan ragam hias Damar Kurung pada target audience melalui sebuah fashion yang gayanya disesuaikan dengan trend di kalangan target audience. 
Konsep pemotretan, styling dan make up pada perancangan ini menampilkan gaya yang lebih kasual, disesuaikan dengan gaya foto, styling dan make up yang disukai target audience. Proses pemotretan dilakukan di luar ruangan maupun dalam ruangan, dengan spesifikasi lokasi yang estetik seperti cafe, taman, dan lain sebagainya. Hasil foto nantinya akan disusun kemudian diunggah ke media sosial Instagram dan juga akan dicetak untuk menjadi bahan referensi target audience dengan menggunakan layout yang sederhana dan menarik.

\section{Konsep dan Tujuan Kreatif}

Membuat perancangan visual ragam hias Damar Kurung dalam fashion melalui pendekatan fotografi. Merancang karya fotografi ini ditujukan untuk memperkenalkan dan mendekatkan kembali ragam hias Damar Kurung pada generasi muda yang berada di kota besar Surabaya, Gresik dan sekitarnya, karena generasi muda kurang mengenal Damar Kurung sebagai bentuk ragam hiasnya. Fotografi dapat me-nunjukkan visual ragam hias Damar Kurung dengan jelas dan menarik pada target audience.

\section{Strategi Kreatif}

Pattern Damar Kurung yang digunakan dalam perancangan ini menggunakan gaya gambar minimalis yang disesuaikan dengan selera target audience. Pattern yang dibuat tetap mengikuti pakem yang ada dalam Damar Kurung tradisional. Pattern Damar Kurung menceritakan mengenai aktivitas yang dilakukan oleh perancang. Kemudian pattern diaplikasikan dalam fashion bergaya kasual untuk mendekatkan target audience dengan ragam hias Damar Kurung.

Fashion dengan pattern Damar Kurung tersebut kemudian divisualisasikan dalam media fotografi. Media tersebut dinilai lebih efektif apabila dilihat dari penggunaan sosial media berbasis visual yang kini menjadi kebutuhan yang juga mempengaruhi gaya hidup dan pola pikir masyarakat. Maka dari itu, fotografi dengan mudah dapat menunjukkan visual dan pesan dapat disampaikan tanpa menimbulkan kesalahpahaman pada pengamatnya. Tema yang diambil dalam perancangan foto ini adalah fotografi editorial ragam hias Damar Kurung dalam Casual Fashion Style.

\section{Konsep Penyajian}

Untuk memperkenalkan dan menarik perhatian target audience pada ragam hias Damar Kurung dalam fashion dengan menggunakan fotografi, pemilihan ragam hias Damar Kurung yang diaplikasikan dalam fashion menggunakan tiga cerita bertema profan, yang menceritakan kehidupan keseharian target audience seperti aktivitas di kampus atau "ngampus", pergi ke mall atau "ngemall", dan pergi ke kafe atau "ngafe" dengan tetap memperhatikan pakem-pakem yang sudah ditentukan da-lam melukis ragam hias Damar Kurung. Pemilihan tema tersebut berdasarkan dari sejarah Damar Kurung yang memang meng-gambarkan keseharian dan aktivitas di sekitar pelukisnya. Ragam hias Damar Kurung tersebut kemudian diaplikasikan dalam fashion dengan gaya kasual yang disesuaikan dengan selera target audience.

Konsep penyajian berupa fotografi editorial dengan model foto yang mengenakan set fashion item dengan pattern Damar Kurung. Fashion item berupa 6 set atasan dan bawahan yang nantinya dikenakan oleh model dengan wajah yang oriental dan ketimuran, aksesoris tambahan seperti scarf dan aksesoris tambahan lainnya.

Adapun target audience dengan kriteria sebagai berikut:

1. Geografis: tinggal di kota besar seperti Surabaya dan Jakarta, bertempat tinggal di perumahan, perkotaan.

2. Behavioristis: mementingkan kualitas daripada harga, cakap dalam padupadan pakaian, mengikuti tren terkini dalam hal berpakaian, menyukai fotografi terutama di media sosial, pengguna sosial media, menyukai produk lokal, menyukai produk yang unik.

3. Demografis: jenis kelamin wanita, berasal dari kelas sosial menengah keatas, usia 2030 tahun, belum menikah.

4. Psikografis: memiliki banyak teman, open minded, berani mencoba hal baru, berani tampil beda.

Judul keseluruhan proses pemotretan ini adalah Ceritera Wastra, artinya adalah ragam hias Damar Kurung yang bercerita mengenai aktivitas masyarakat sehari-hari yang dituangkan dalam wastra yang berarti kain. Pemotretan dilakukan secara indoor di dalam Prime Studio, Jl. Taman Jemursari 
Selatan I no. 19, Surabaya untuk mendapatkan pen-cahayaan yang sesuai dan mewujudkan konsep pemotretan dalam perancangan ini. Properti yang digunakan saat proses pemotretan adalah 6 set busana, scarf, aksesoris rambut, goodie bag, shoulder bag, meja, kursi, cangkir kopi dan piring, makanan, buku, kertas dan map, serta laptop.

Pemotretan lebih fokus pada ragam hias Damar Kurung sehingga banyak menggunakan teknik close up untuk memfokuskan frame pada ragam hias Damar Kurungnya, pengambilan sudut gambar menggunakan eye level. Medium shot dan long shot juga akan digunakan untuk menampilkan keseluruhan style fashion yang dikenakan oleh model, pengambilan sudut gambar menggunakan eye level. Proses editing dilakukan untuk menyamakan tone warna antar foto, menghilangkan noda dan benda yang tidak diinginkan seperti lighting, brand pada goodie bag, jerawat, flek hitam pada wajah, dan lain sebagainya. Proses editing juga dilakukan agar pattern yang semula kurang terlihat jadi terlihat dengan mengatur kontrasnya.

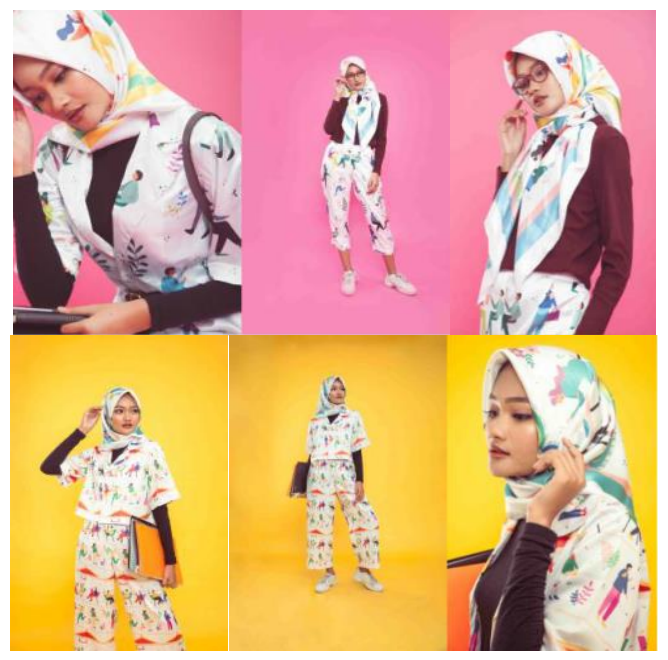

Gambar 1. Foto tema "Ngampus"

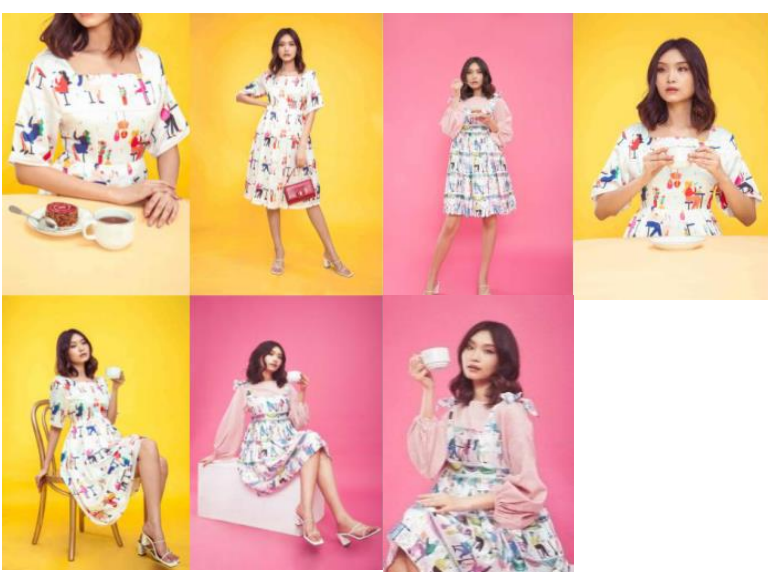

Gambar 2. Foto tema "Ngafe"

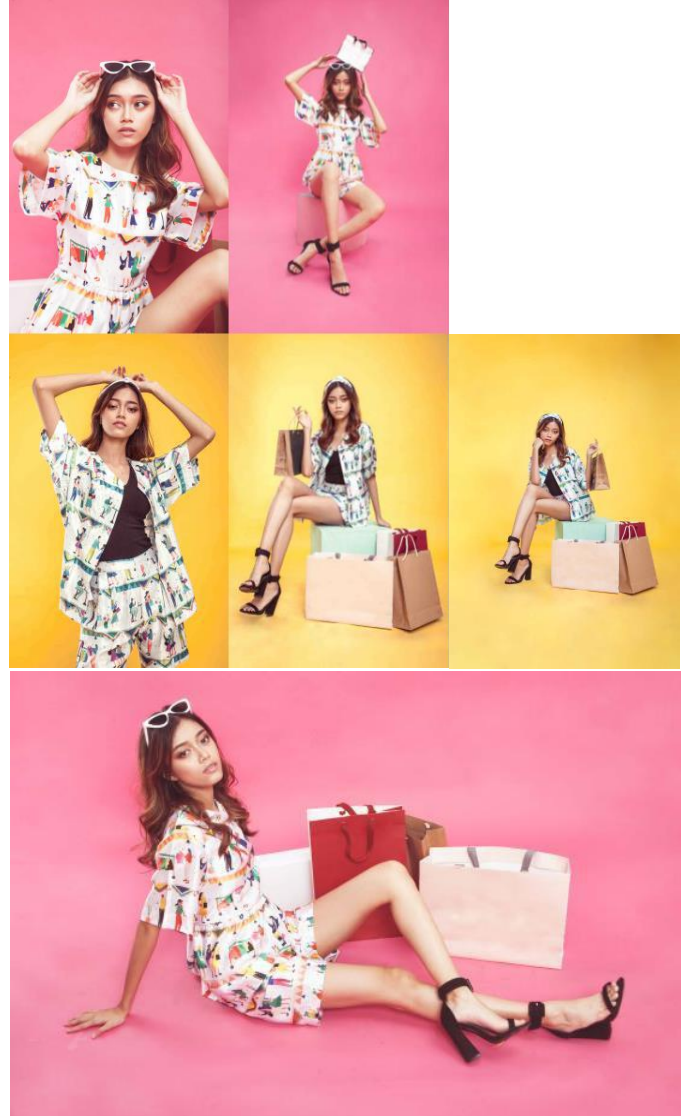

Gambar 3. Foto tema "Ngemall"

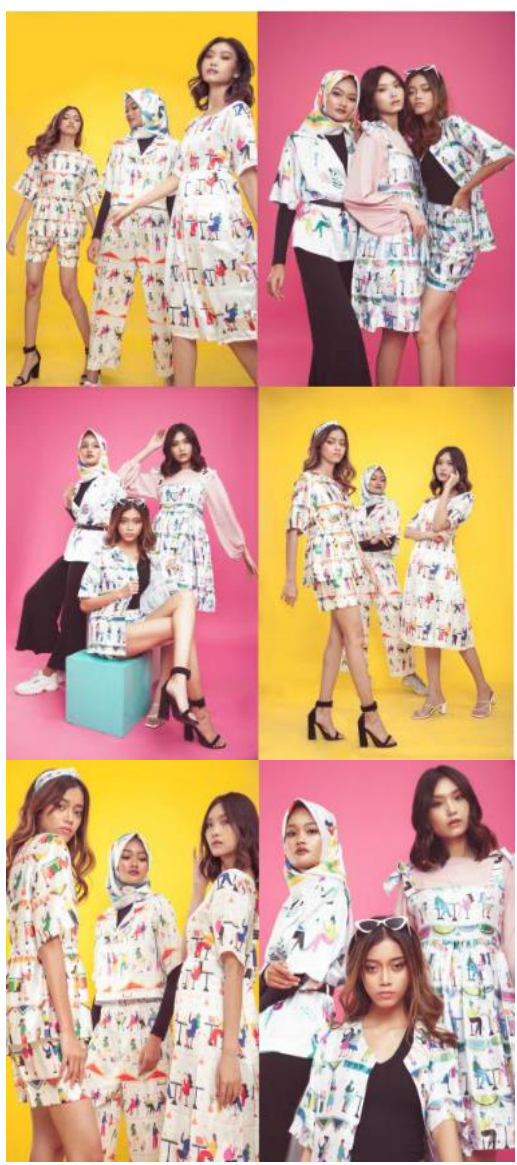

Gambar 4. Foto Berkelompok 


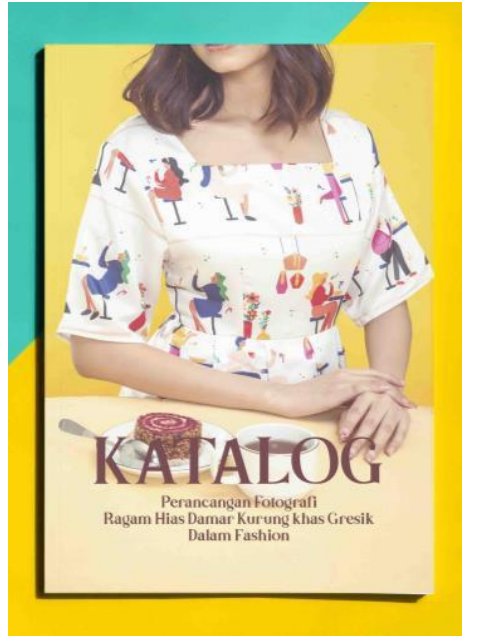

(a)

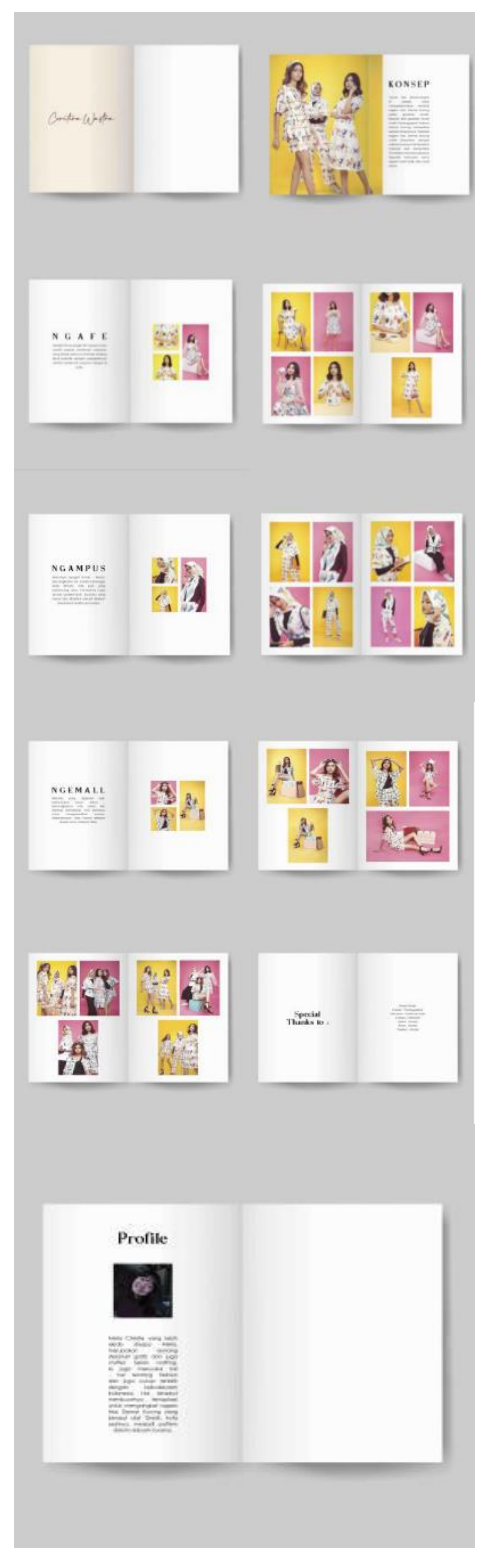

(b)

Gambar 5. Layout buku katalog

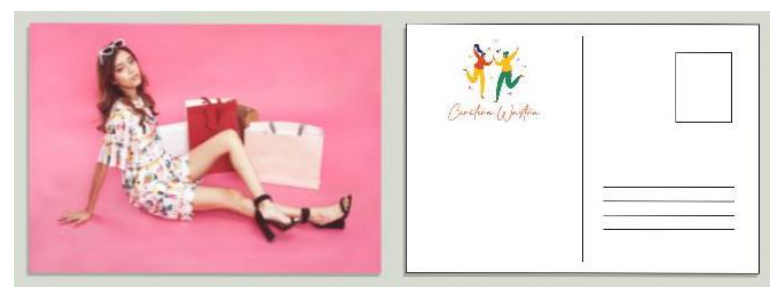

Gambar 6. Layout postcard

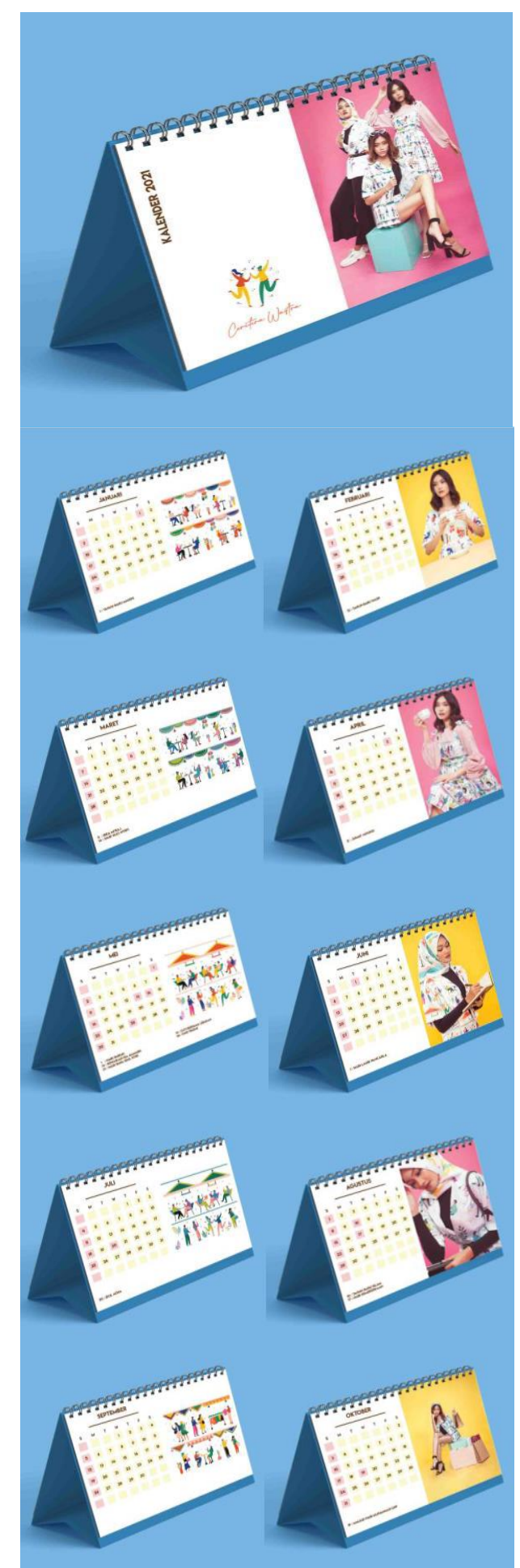

Gambar 7. Tampilan Kalender 


\section{Simpulan}

Dalam proses perancangan fotografi ragam hias Damar Kurung khas Gresik dalam fashion ini dapat diketahui bahwa banyak nilai sejarah yang terus berkembang dari masa ke masa. Melalui fotografi ini, nilai sejarah tersebut dikomunikasikan pada target audience secara estetis dan menarik. Perancangan ini diharapkan dapat memberikan wawasan mengenai budaya daerah Nusantara lebih luas lagi bagi masyarakat. Karya foto ini menggunakan 3 model yang mengenakan set pakaian dengan pattern ragam hias Damar Kurung yang masing-masing memiliki tema aktivitas keseharian masa kini. Setiap frame ditampilkan dengan gaya yang kasual, menyesuaikan dengan selera target audience yang kini lebih banyak tampil dengan gaya tersebut. Observasi dilakukan melalui wawancara dengan Novan Effendy selaku pendiri Damar Kurung Institute untuk mencari tahu lebih dalam tentang ragam hias Damar Kurung. Dapat disimpulkan bahwa selama mengerjakan perancangan fotografi ini, kemampuan yang dibutuhkan bukan hanya hardskill atau proses eksekusi desain dan lainnya, tapi juga perlu adanya soft skill atau kemampuan bekerja sama dan berkomunikasi dengan tim agar proses perancangan dapat berjalan dengan baik dan sesuai dengan yang diharapkan.

\section{Daftar Pustaka}

Admin. 2017, 20 Teknik Komposisi Foto untuk Meningkatkan Skill Fotografi, Retrieved from: https://www.kamerashot.com/belajarkomposisi-foto/

Andina, Y. 2019, Mengenal 11 Jenis Aturan Komposisi dalam Fotografi, Retrieved from: https://kreativv.com/fotografi/komposisidalam-fotografi/

Andina, Y. 2020, Mengenal Fashion Photography dan Jenis-Jenisnya. Retrieved from: https://kreativv.com/fotografi/fashionphotography/

Annisaa, R. 2014, Damar Kurung: Perjalanan Kesenian Tradisi Rakyat Gresik, Dukut Publishing, Surabaya.

Ardiati, S. 2017, Teknik-Teknik Fotografi. Retrieved from: https://www.kompasiana.com/shellyardiati1 1/59e6f98863eae71a3f63a072/teknik-

teknik- fotografi

Awaliyah, F. 2020, Pengertian Fotografi Menurut Para Ahli dan Jenis Fotografi. Retrieved from: https://sukagitu.com/pengertian-fotografi/

Christianna, A., dan Renaningtyas, L. 2017/2018, Penelitian Ragam Hias Damar Kurung Sebagai Pengembangan Motif Batik Khas Gresik. Universitas Kristen Petra, Surabaya.

Editor02. 2017, Damar Kurung Diakui Sebagai Warisan Budaya, Retrieved from: http://www.kabargresik.com/damarkurung-diakui-sebagai-warisan-budaya/

Gitgita. 2018, Sejarah Asal Mula dan Nama Kota Gresik, Retrieved from: http://sejarahunik.net/sejarah-kota/sejarahasal-mula-dan-nama-kota-gresik.html

International Design School. 2015, Arti Fotografi Menurut Para Ahli. Retrieved from:https://idseducation.com/articles/fotogr afi- menurut-para-ahli/

Karyadi, B. 2017, Fotografi. NahlMedia, Bogor.

Koeshandari, I. I. 2009, Damar Kurung dari Masa ke Masa. Dewan Kesenian Jawa Timur, Surabaya.

Kusumabrata, R. 2015, Fotografi Fashion \& Beauty Shot. Retrieved from: http://www.rkusumabrata.com/post/fotograf i-fashion-beauty-shot

Nahak, H. M. 2019, Upaya Melestarikan Budaya Indonesia di Era Globalisasi. Jurnal Sosiologi Nusantara, p. 65-76.

Setiawan, S. 2020, Pengertian Fashion-Stylist, Sejarah, Manfaat, Ciri, Perkembangan, Faktor, Para Ahli, Retrieved from: https://www.gurupendidikan.co.id/pengertia n-fashion/

Thalia, N. 2019, Macam-Macam Fashion Styles Ini, Menggambarkan Kepribadianmu! Style Kamu Yang Mana Nih? Retrieved from: https://www.theshonet.com/articles/macammacam-fashion-styles-yangmenggambarkan-kepribadianmu

Tim kamerabudaya.com. 2018, Batik GresikSejarah, Motif, Ciri Khas, Filosofi, Makna dan Perkembangannya. Retrieved from: https://www.kamerabudaya.com/2018/06/ba tik-gresik-sejarah-motif-ciri-khas-filosofimakna-dan-perkembangannya.html 